\title{
Effect of the Nutritional Supplement VIUSID Vet on the Productivity of Fattening Pigs in a Low-Input Farming System
}

Juan Carlos Rodríguez-Fernández ${ }^{1}$, Vicente Méndez-García ${ }^{1}$, Ibraín Calero-Herrera ${ }^{1}$, Kolima Peña-Calzada ${ }^{1}$, Osdany Martínez-Torres ${ }^{2}$ and Jorge Gómez-Abdura ${ }^{3}$

1. Department of Veterinary Medicine and Animal Husbandry, University of Sancti Spiritus, Sancti Spiritus 60100, Cuba

2. Department of Production, Swine Farm of Jatibonico, Jatibonico 62200, Cuba

3. Veterinary Laboratory, Provincial Institute of Veterinary Medicine, Sancti Spiritus 60100, Cuba

\begin{abstract}
The objective of the study was to evaluate the effect of the nutritional supplement VIUSID vet on the mortality and the productivity behaviour of fattening pigs in a low-input farming system. Two experiments were carried out at a pig farm in the municipality of Jatibonico, Sancti Spíritus province, Cuba. The farm has a low level of specialization, pigs are fed using local resources such as sugarcane (Saccharum officinarum) juice and locally produced concentrated feed. In both studies, the treatment consisted in administering together with the feed $2.0 \mathrm{~g}$ of VIUSID vet per $\mathrm{Kg}$ of feed. Results showed that in low-input rearing conditions, supplying VIUSID vet significantly reduced deaths $(17.65 \%)$ in the pigs treated, favoured leukocyte and lymphocyte counts, and significantly improved weight gain (16.33\%) and feed efficiency (14.41\%).
\end{abstract}

Key words: VIUSID, pigs, additive, Glycyrrhiza glabra.

\section{Introduction}

The pig industry aims to increase production of meat at less cost with a lower impact on the environment as opposed to previous decades. There are several factors that influence the aforementioned. One of the key factors is nutrition, especially during the fattening stage, when a considerable amount of money spent on feed. Another factor that might contribute to the animals not attaining their maximum growth potential is poor sanitation, due to the fact that if pigs are sick, their appetite and consumption is reduced.

Feeding animals is certainly complex and far-reaching, especially when it comes to feeding pigs during the fattening stage, which is one of the most difficult challenges that a nutritionist might have to deal with. Whether it is due to the latest advances in

Corresponding author: Juan Carlos Rodríguez, Ph.D., main research field: animal nutrition. the use of different new additives and ingredients, new farming methods and technology or the demands of a market has access to increasingly more information and requires quality animal products at a reasonable price.

For example, due to the concern that the use of antibiotics as feed additives may contribute to an increase in bacterial resistance, the European Union decided to prohibit the use of antibiotics as feed additives from January 1st 2006. Therefore, many alternatives to establish other substances with similar beneficial effects have started to be evaluated [1].

In addition, the aim is for new food additives to be safe for people and the environment, especially help reduce the pollutant load of rearing animals by improving feed efficiency.

Several studies confirm that the use of synthetic amino acids as a nutritional supplement leads to a decrease of $33 \%$ in the excretion of faeces and $20 \%$ nitrogen in fattening pigs [2]. The supplement 
assessed in this research (VIUSID vet) includes amino acids, vitamins, minerals and glycyrrhizinic acid, which is an extract from the root of the liquorice (Glycyrrhiza glabra) plant. It is a substance with antibacterial and antiviral properties, thus, constituting an excellent alternative to the use of antimicrobial agents to improve production without the disadvantage of resting times or the presence of pharmaceutical/chemical residue [3].

The components of VIUSID vet are subjected to a process of molecular activation, which allows favourable results in animal farming without affecting people and the environment using minimal doses [4].

On the other hand, although intensive pig farming is becoming more popular, in many parts of the world including Cuba, a lot of pigs are reared in low or medium specialization conditions. Due to that, new products and/or technology must also be evaluated in these environments, seeing that a high percentage of the population depends on the food produced in these farming conditions. Hence, the objective of the study was to evaluate the effect of administering VIUSID vet on the mortality and productive performance of fattening pigs in a low-input farming system.

\section{Approach and Research Methods}

\subsection{General Aspects}

Two experiments took place at a pig farm in the municipality of Jatibonico, Sancti Spíritus province, Cuba. The farm has a low level of specialization, pigs are fed using local resources such as sugarcane (Saccharum officinarum) juice and locally produced concentrated feed. The feed used for the trials contains $88.62 \%$ dry matter, $17.8 \%$ crude protein in a wet base and $2.66 \mathrm{mcal} / \mathrm{kg}$ of digestible energy.

VIUSID vet contains malic acid, glucosamine, arginine, glycine, ascorbic acid, folic acid, monoammonium glycyrrhizinate (Glycyrrhiza glabra root extract), pyridoxine hydrochloride, cyanocobalamin, calcium pantothenate and zinc sulphate. Moreover, it undergoes a biocatalytic process of molecular activation, which significantly improves biological activity and biochemical reactivity of all molecules.

In both experiments, statistical software SPSS 15.0.1 (2006) for Windows and MINITAB release version 14.12 .0 were used $[5,6]$.

\subsection{Approach and Research Methods of Experiment 1}

Thirty three fattening pigs were used-17 were assigned to the control group and 16 to the treatment group, with an average initial weight of $33.19 \mathrm{~kg}$. The animals were identified and each pig was considered to be one experimental unit. The treatment consisted in administering $2.0 \mathrm{~g}$ of VIUSID vet powder per $\mathrm{kg}$ of feed. The clinical trial lasted 52 days.

Variables in the clinical trial:

(1) Independent: using VIUSID vet powder as an additive in the pigs' feed during the fattening stage;

(2) Dependent:

- Mortality rate: percentage of pigs that died in each group;

- Haematological variables: haematocrit (Hct, \% ), haemoglobin $(\mathrm{Hb}, \mathrm{g} / \mathrm{dL})$, total leukocyte count (leuc./L), segmented neutrophils (\%), lymphocytes $(\%)$, other cells $(\%)$ and plasma protein $(\times 10 \mathrm{~g} / \mathrm{L})$.

Blood samples were collected from 22 pigs for the haematological study (12 treated and 10 controls) when they had been consuming VIUSID for 40 days. The blood ( $4 \mathrm{~mL}$ per pig) was taken from the orbital venous sinus and EDTA was used as an anticoagulant. They were analysed in the biology laboratory at the Universidad de Sancti Spíritus.

Statistical analysis: to evaluate the haematological variables, t-tests were used for data with homogeneity of variance after normal distribution of the data (Kolmogorov-Smirnov test for a sample) and the homogeneity of variance (Levene test) were verified. The mortality rate was determined by means of hypothesis testing for ratios.

\subsection{Approach and Research Methods of Experiment 2}

Twenty fattening pigs were used-10 were 
assigned to the control group and 10 to the treatment group. The animals were identified and each pig was considered to be one experimental unit. The treatment consisted in administering $2.0 \mathrm{~g}$ of VIUSID vet powder per $\mathrm{kg}$ of feed daily. The clinical trial lasted 50 days. The rearing conditions were suitable for a non-specialized farming system.

Variables in the clinical trial:

(1) Independent: using VIUSID vet powder as an additive in the feed for fattening pigs;

(2) Dependent:

- Final weight: this was determined by weighing the animals at the end of the experiment, expressed in $\mathrm{kg}$;

- Weight gain: this was determined by calculating the differences between the initial and the final weights and was expressed in $\mathrm{kg}$;

- Feed conversion: feed consumed per unit of weight gain, expressed in $\mathrm{kg} / \mathrm{kg}$.

Statistical analysis: T-tests were used for data with homogeneity variance, after normal distribution (Kolmogorov-Smirnov test) and equal variance (Levene test) were verified.

\section{Results and Discussion}

\subsection{Results and Discussion of Experiment 1}

For this first experiment, the farm had increasing mortality due to feed irregularities. It was decided to evaluate the effectiveness of VIUSID vet in these conditions and it was noted that with its use pig mortality decreased significantly $(\mathrm{p} \leq 0.05)$ when compared with control units (Fig. 1).

Pneumonia was the cause of all deaths (Fig. 2). In Cuba, the most recurrent is the enzootic produced by Mycoplasma hyopneumoniae, which is a highly contagious disease characterized by the presence of respiratory symptoms and low mortality. When secondary infections by bacteria are present, which is common, very serious affections are created that lead to large financial losses. Concomitant infections are caused mainly by Pasteurellas, Mycoplasma hyorhinis, Haemophilus parasuis and Actinobacillus pleuropneumoniae [7].

VIUSID could have influenced a greater immune response to infections and hence the lower mortality in the treated units. Mexican researchers reported that

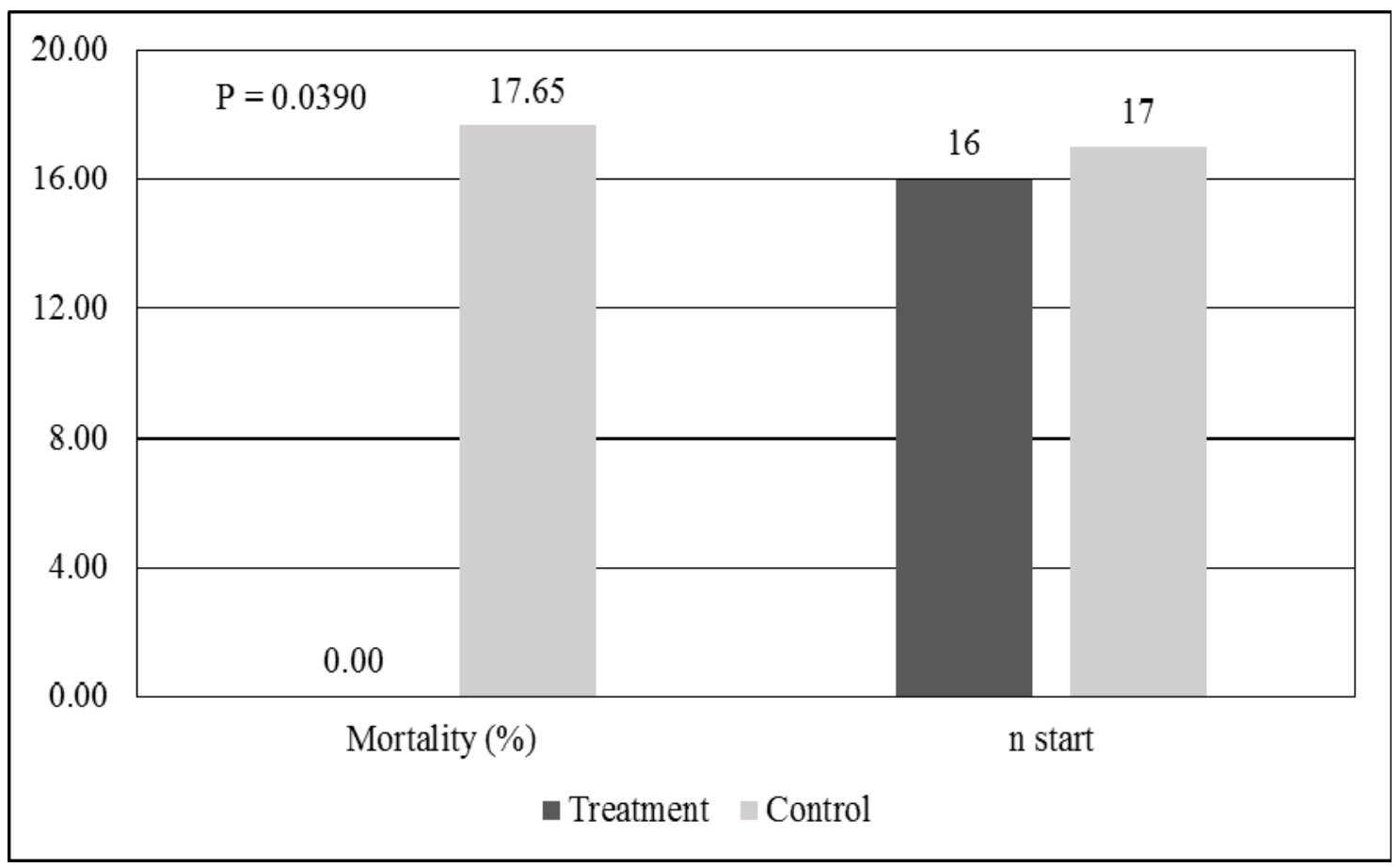

Fig. 1 Effect of administering VIUSID vet on the incidence of deaths in the experiment. 

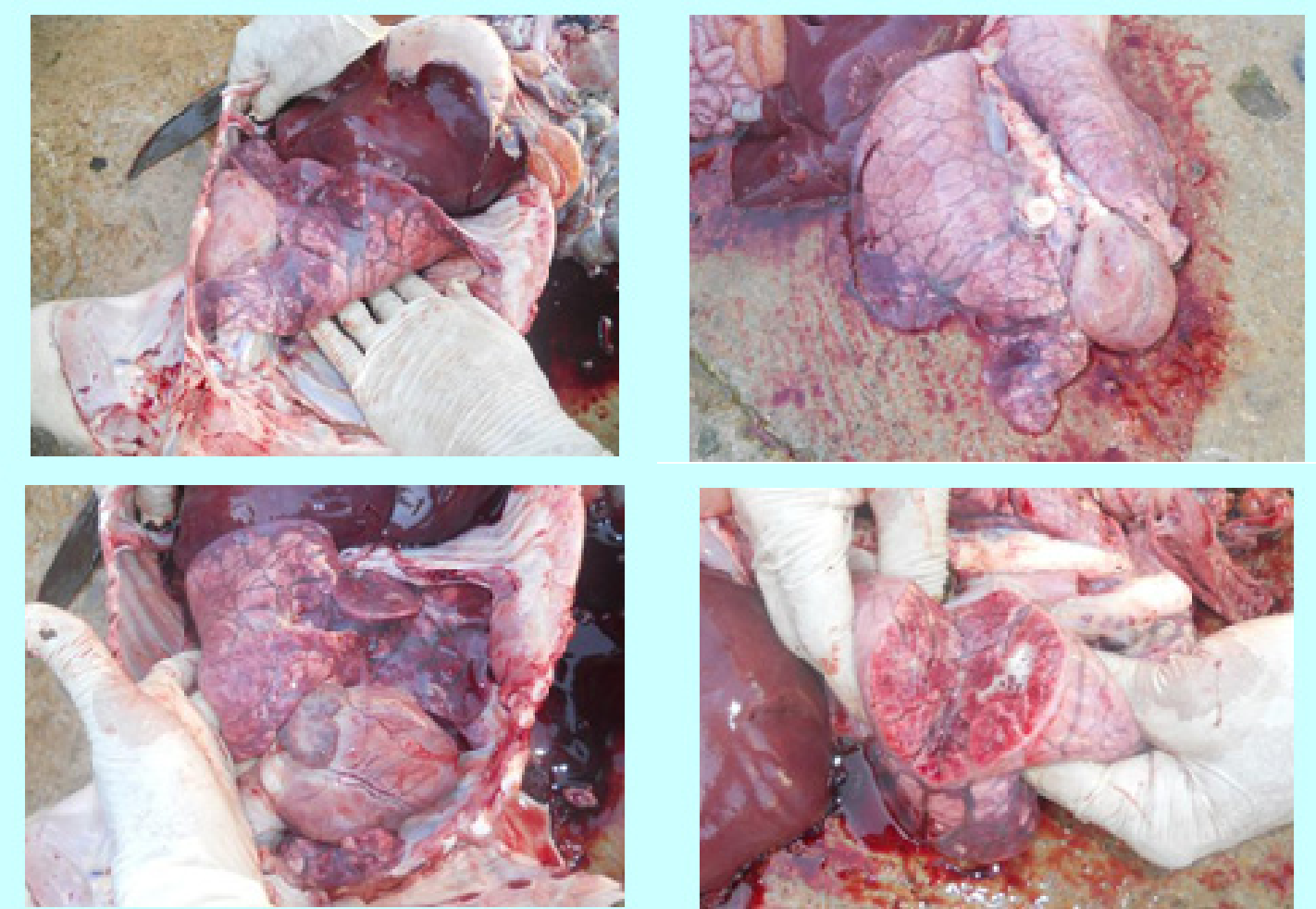

Fig. 2 Photograph of the main lesions observed during the experiment in an necropsy carried out on a pig that presented severe respiratory symptoms.

with the use of VIUSID vet powder in feed for fattening pigs, the defences of the organisms improved, which is measured through a haemagglutination inhibition test and real RT-PCR for swine influenza virus subtypes H1N1 and H3N2 [8].

The components of VIUSID confer immunomodulatory and antiviral properties, which is very important to counteract infectious diseases. One of its components, monoammonium glycyrrhizinate, possesses antiviral properties proven in previous studies in humans $[9,10]$.

As research conducted with the product in pigs is still in its infancy, many of its effects on this species have yet to be studied. However, in humans, the antiviral properties of glycyrrhizinic acid have been proven in the hepatitis virus, respiratory syncytial virus and others, such as HIV and Flavivirus [9-15].

It has been determined that the mechanism of antiviral action of glycyrrhizinic acid works by inhibiting the replication of the Flaviviruses through the protein phosphorylation of kinase-P [16]. It is also put forward that it can improve this cellular response by enhancing the host's immune response to infection, according to randomized studies [17, 18]. VIUSID also stimulates the production of interleukin-12 in macrophages, facilitating the production of interferons, which promotes the activation of alveolar macrophages and, as a result, increases their destructive and phagocytic properties against microorganisms [19].

The effect of the treatment on haematological variables is shown in Table 1. After 40 days of treatment, it was found that the animals who received the product had a significantly higher leukocyte values than control. Nevertheless, both groups were within the normal range for the species. The average value observed in pigs in the control group is the minimum limit deemed acceptable by several authors [20, 21]. The other variables did not differ among one another.

Table 2 shows the result of differential leukocyte count. No significant statistical differences were found between both groups, although a lower number of eosinophils and a greater number of lymphocytes were 
Table 1 Behaviour of the global haematological values in the experiment (mean \pm standard deviation).

\begin{tabular}{lllll}
\hline Variables & $\mathrm{U} / \mathrm{M}$ & Control & Treatment & $\mathrm{P}$ \\
\hline Samples & $\mathrm{u}$ & 10 & 12 & \\
Haematocrit & $\%$ & $41.20 \pm 4.34$ & $38.92 \pm 2.35$ & 0.15 \\
Haemoglobin & $\mathrm{g} / \mathrm{dL}$ & $12.36 \pm 1.30$ & $11.68 \pm 0.70$ & 0.15 \\
Leukocytes & Leuc./L & $11,775.0 \pm 3,095.6$ & $15,416.6 \pm 4,994.1$ & 0.05 \\
\hline
\end{tabular}

Table 2 Results of the differential leukocyte count (mean \pm standard deviation).

\begin{tabular}{lllll}
\hline Variables & $\mathrm{U} / \mathrm{M}$ & Control & Treatment & $\mathrm{P}$ \\
\hline Samples & $\mathrm{u}$ & 10 & 12 & \\
Segmented & $\%$ & $40.20 \pm 5.90$ & $40.83 \pm 15.35$ & 0.925 \\
Eosinophils & $\%$ & $8.70 \pm 13.96$ & $2.75 \pm 2.05$ & 0.405 \\
Lymphocytes & $\%$ & $51.10 \pm 12.05$ & $56.41 \pm 16.36$ & 0.213 \\
\hline
\end{tabular}

observed in most of the units treated, though theses were considered normal for the species.

Table 3 provides additional information on how many animals in each group showed values that are not within the range considered normal. Statistically, only significant differences were found $(p<0.05)$ in the leukocyte count, where $50 \%$ of the animals in the control group had values below the lower limit as opposed to just $16.6 \%$ of those treated, leading to the consideration that they were suffering slight leukopenia.

The result obtained on leukocytes was due to the amount of stress that these pigs were under, given the rearing characteristics and their poor physical condition. The normal values obtained by the pigs from the treatment group are linked to the effect of the product, which helped against the stress that they were under.

Stress leukograms have a typical differential leukocyte count that includes a mature neutrophilia, lymphopenia and eosinopenia. The lymphocytes are major cells in the immune system and they are basically in charge of a specific or acquired immunity, which is why the immunomodulatory effect of VIUSID is thought to have had a positive effect on the increase of the lymphocytes and the leukocytes in the pigs from the treatment group.

VIUSID counteracts the effect of oxidative stress through the reduction of lipid peroxidation products and the immunomodulatory effect of cytokine secretion. An increase in the production of IFN and IL-10, reduced production of IL-1, and stabilized TNF were observed in patients with chronic hepatitis C [4].

When sick people are treated with VIUSID, a more efficient response in global leukocyte count data in the experimental group is observed in relation to the control group, becoming normalized practically by the sixth day and decreasing the number of neutrophils in relation to the experimental group, which demonstrates better control of the infectious process in treated subjects [22].

\subsection{Results and Discussion of Experiment 2}

Table 4 shows the results of supplying VIUSID to fattening pigs. Statistical analysis showed significant differences $(p<0.05)$ between treatments for the variables "increase in weight" and "feed conversion" in favour of treated pigs.

The weight gained by the animals was thanks to the fact that the feed was used more efficiently by the pigs which were treated with VIUSID. The improvement seen in the variables were statistically different which was higher than $16 \%$ and $14 \%$. The feed conversion values are not good due to the fact that although the feed administered had a high crude protein content, in terms of its energy value, it did not fulfil the requirements established for the category (2.66 $\mathrm{mcal} / \mathrm{kg}$ ). There were no deaths or cases of diarrhoea in either group. 
Table 3 Animals with values outside the normal ranges by treatment (n (\%)).

\begin{tabular}{llllll}
\hline Variables & \multicolumn{3}{c}{ Control } & \multicolumn{1}{l}{ Treatment } & Normal range \\
\hline Samples & 10 & & 12 & \\
\hline Level & $<$ & $>$ & $<$ & $>$ & \\
\hline Haematocrit & $1(10)$ & $3(30)$ & $1(8.33)$ & $1(8.33)$ & $36-43$ \\
Haemoglobin & 0 & $3(30)$ & 0 & $1(8.33)$ & $9-13$ \\
Leukocytes & $5(50)$ & 0 & $2(16.6)$ & $1(8.33)$ & $11,000-22,000$ \\
Segmented neutrophils & $1(10)$ & $3(30)$ & $1(8.33)$ & $3(25)$ & $20-70$ \\
Eosinophils & 0 & $1(10)$ & 0 & 0 & $0-15$ \\
Lymphocytes & $1(10)$ & 0 & $1(8.33)$ & $1(8.33)$ & $35-75$ \\
Plasma protein & 0 & 0 & 0 & 0 & $6-8$ \\
\hline
\end{tabular}

Table 4 Behaviour of the indicators related to weight gain (mean \pm standard deviation).

\begin{tabular}{lllll}
\hline Variables & $\mathrm{U} / \mathrm{M}$ & Treatment & Control & $\mathrm{p}$ \\
\hline Initial $\mathrm{n}$ & $\mathrm{u}$ & 10 & 10 & 10 \\
Final $\mathrm{n}$ & $\mathrm{u}$ & 10 & $41.42 \pm 20.86$ & 0.646 \\
Initial weight & $\mathrm{kg}$ & $46.30 \pm 25.64$ & $17.33 \pm 1.50$ & 0.000 \\
Weight gain & $\mathrm{kg}$ & $20.16 \pm 0.81$ & $7.08 \pm 0.65$ & 0.001 \\
Feed conversion & $\mathrm{kg} / \mathrm{kg}$ & $6.06 \pm 0.49$ & & \\
Improvement in weight gain & $\%$ & 16.33 & & \\
Improvement in feed conversion & $\%$ & 14.41 & & \\
\hline
\end{tabular}

The improvement in feed efficiency (14.41\%) favours a reduction in environmental pollution. It is widely known that the higher efficiency of food utilization by pigs, the less faeces are produced, although this was not measured in the experiment.

With the use of the product in fattening pigs in Mexico, they found that the use of a dose of $2 \mathrm{~kg}$ per tonne of food improved productive parameters, the mean daily gain by 89 grams and feed conversion by 90 grams [8].

With a dosage of 1.5 grams of VIUSID vet powder per $\mathrm{kg}$ of feed for fattening pigs in Cuba, there was a significant increase in weight gain and feed conversion rate in the treated pigs, mainly in the initial stage [23].

The components of VIUSID confer antiviral (malic acid and glycyrrhizinic acid), antioxidant (malic acid, ascorbic acid and glycyrrhizinic acid), antianemic (folic acid, cyanocobalamin and pyridoxine), immunomodulatory (arginine, glycine, glycyrrhizinate, calcium pantothenate and zinc) and biocatalytic (zinc and calcium pantothenate) properties. For example, zinc is an important trace mineral in conjunction with copper, which is needed by pigs for many metabolic functions. The inclusion of these minerals in their diet improves their rate of growth, especially in young pigs [24].

Most enzymes in pigs require zinc in their structure to function normally, it is an essential part of insulin. Pigs with deficient levels of zinc show poor growth, poor appetite and parakeratosis [25].

Other trials prove that supplementing with arginine in the diet stimulates protein synthesis in the skeletal muscles of young pigs $[26,27]$. There is growing evidence that arginine has an important role in the regulation of energy metabolism [28].

\section{Conclusions}

In low input rearing conditions, supplying VIUSID vet significantly reduced deaths in fattening pigs, favoured leukocyte and lymphocyte counts, and significantly improved weight gain and feed efficiency.

\section{References}

[1] Ortwin, S. 2005. "Micro-organisms as Feed Additives-Probiotics." Advances in Pork Production 16: 161. 
[2] Viaene, J., and Verbeke, W. 1998. "Economic Feasibility of the Use of Feed Additives." Pig Progress 14 (3): 11-14.

[3] Tanaka, Y. 2001. "Antibacterial Compounds of Licorice against Upper Airway Respiratory Tract Pathogens." $J$. Nutr. Sci. Vitaminol 47 (3): 270-273.

[4] Vilar, E., Martínez, Y., Vega, H., Arus, E., Calzadilla, L., and Yasells, A. et al. 2010. "Antioxidant and Immunomodulatory Effects of VIUSID in Patients with Chronic Hepatitis C." World J. Gastroenterol 16 (21): 2638-2647.

[5] SPSS. 2006. Statistical Package for the Social Sciences (SPSS), Version 15.0.1. Chicago: SPSS Inc.

[6] MINITAB. 2003. Statistical Software Minitab Release 14.12.0. Pennsylvania: Minitab Inc..

[7] Alonso, R., Cama, J. M., and Rodríguez, J. 2004. The Pig. La Habana: Felix Varela. (in Spanish)

[8] Ocampo, L., and Sánchez, I. 2012. "Evaluation of the Effectiveness of VIUSID Vet Powder on Productive and Immunologic Indicators in Fattening PIGS." Los Porcicultores y Su Entorno 15 (85): 98-102. (in Spanish)

[9] Ito, M., Sato, A., and Hirabayashi, K. 1988. "Mechanism of Inhibitory Effect of Glycyrrhizin on Replication of Human Immunodeficiency Virus (HIV)." Antiviral Res. 10: 289-298.

[10] Baba, M., and Shigeta, S. 1987. "Antiviral Activity of Glycyrrhizin against Varicella-Zoster Virus in Vitro." Antiviral Res. 7: 99-107.

[11] Takahara, T., Watanabe, A., and Shiraki, K. 1994. "Effects of Glycyrrhizin on Hepatitis B Surface Antigen: A Biochemical and Morphological Study." J. Hepatol. 21: 601-609.

[12] Van Rossum, T. G. J., Vulto, A. G., Hop, W. C. J., Brouwer, J. T., Niesters, H. G. M. and Schalm, S. W. 1999. "Intravenous Glycyrrhizin for the Treatment of Chronic Hepatitis C: A Double-Blind, Randomized, Placebo-Controlled Phase I/II Trial.” J. Gastroenterol Hepatol. 14: 1093-1099.

[13] Wang, X. Q., Li, H. Y., and Liu, X. Y. 2006. "The Anti-respiratory Syncytial Virus Effect of Active Compound of Glycyrrhiza GD4 in Vitro." Zhang Yao Cal. 29: 692-694.

[14] Badam, L. 1997. "In Vitro Antiviral Activity of Indigenous Glycyrrhizin, Licorice and Glycyrrhizic Acid (Sigma) on Japanese Encephalitis Virus.” J. Commun Dis. 29: 91-99.

[15] Crance, J. M., Scaramozzino, N., Jouan, A., and Garin, D. 2003. "Interferon, Ribavirin, 6-Azauridine and Glycyrrhizin: Antiviral Compounds Active against Pathogenic Flaviviruses.” Antiviral Res. 58: 73-79.

[16] Ohtsuki, K., and Iahida, N. 1988. "Inhibitory Effect of Glycyrrhizin on Polypeptide Phosphorylation by
Polypeptide-Dependent Protein Kinase (Kinase P.) in Vitro." Biochem. Biophys. Res. Commune 157: 597-604.

[17] Fiore, C., and Eisenhut, M. 2008. "Antiviral Effects of Glycyrrhiza Species.” Phytother Res. 22: 141-148

[18] Hsueh-Hsia, L., and Yee-Sang, Y. 1997. "Glycyrrhizic Acid Inhibits Arylamine N Acetyltransferase Activity in Klebsiella Pneumoniae in Vitro." Journal of Applied Toxicology 17 (6): 385-390.

[19] Di-Mambro, V. M., and Fonseca, M. J. V. 2005. "Assays of Physical Stability and Antioxidant Activity of a Topical Formulation Added with Different Plant Extracts." J. Pharm. Biomed. Anal. 37: 287-295.

[20] Mundo-Pecuario. 2012. "Valores Hemáticos Normales." Accessed November $\quad 15,2013$. http://www.mundo-pecuario.com/tema104/sanidad_anim al/valores_hematicos-86.html.

[21] Ramírez, E., Ruiz, A., Islas, A., Lecocq, C., Carrasco, L., and Quezada, M. 2006. "Characteristic Haematological and Pathological of Pigs Inoculated Experimentally with the Isolated Chilean of the PRRS Virus." Arch. Med. Vet. 38: 151-159.

[22] Hernández, G., Carrasco, M., García, R., Gómez, M., Alarcón, C., and Garofalo N. 2012. "Evolution Clinical-Haematological of Patient with Syndrome Feverish Sharp Treaties with the Nutritional Supplement VIUSID." Revista Cubana de Tecnología de la Salud 3 (3): 144-152. (in Spanish)

[23] Rodríguez, J. C., Méndez, V., Calero, I., Peña, K., and Gómez, G. 2015. "Behavior of Fattening Pigs Fed with a Nutritional Supplement Activated Molecularly." In Proceedings of the VI International Seminar Porcicultura Tropical, 225.

[24] Jacela, J. Y., De-Rouchey, J. M., Tokach, M. D., Goodband, R. D., Nelssen, J. L., and Renter, D. G. et al. 2010. "Feed Additives for Swine: Fact Sheets-High Dietary Levels of Copper and Zinc for Young Pigs and Phytase." J. Swine Health Prod. 18 (2): 87-91.

[25] The Pig Site. 2014. "Pig Health, Zinc." Accessed January 18 , 2015. http://www.thepigsite.com/pighealth/article/546/zinc.

[26] Kim, S. W., and Wu, G. 2004. "Dietary Arginine Supplementation Enhances the Growth of Milk-Fed Young Pigs." J. Nutr. 134: 625-630.

[27] Yao, K., Deng, D., Liu, Z. Q., Li, T. J., Huang, R. L., and Chu, W. Y. et al. 2008. "Dietary Arginine Supplementation Increases Intracellular MTOR Signaling Activity in Skeletal Muscle of Neonatal Pigs." J. Nutr. 138: 867-872.

[28] Jobgen, W. S., Fried, S. K., Fu, W. J., Meininger, C. J., and Wu, G. 2006. "Regulatory Role for the Arginine-Nitric Oxide Pathway in Metabolism of Energy Substrate.” J. Nutr. Biochem. 17: 571-588. 